\title{
FESAEI: a fuzzy rule-based expert system for the assessment of environmental impacts
}

\section{A fuzzy logic approach to impact assessment} AQ1

José E. de Tomas Sánchez, $\mathrm{PhD}^{1 \square}$
Phone: +34 965903554
Email: je.tomas@ua.es

Sergio de Tomás Marín, $\mathrm{MSc}^{2}$

Victoriano Peiró Clavell, $\mathrm{PhD}^{1}$

1 Faculty of Science, Department of Ecology, University of Alicante, Ctra. de Alicante, s/n, 03690 San Vicente del Raspeig, Alicante, Spain

2 New Mexico Institute of Mining and Technology, Socorro, NM, USA

Received: 17 January 2018 / Accepted: 7 August 2018

\section{Abstract}

Currently, the method mostly used by practitioners of environmental impact assessment (EIA) is the "crisp numbers" method. Nevertheless, this arithmetic method is far away of giving correct values due to its rigidity and the lack of consideration of important aspects as the imprecision and incompleteness of data and the uncertainty that usually pervade our knowledge of environment. A more flexible model that considers uncertainty of knowledge and imprecision of data is necessary. Among the different approaches for the assessment of environmental impacts, the fuzzy logic-based one takes account of the aspects said 
before; this was our primal assumption. On this paper, we explain the structure and performance of the fuzzy rule-based inference model we built, how it works, and what can be obtained when used to assess environmental impacts. Our fuzzy expert system for the assessment of environmental impacts (FESAEI) is built as the combination of five subsystems, using a total of 120 fuzzy rules, and being the output and input for the next subsystem. We assessed the parameters of rarity, robustness, quality, recoverability, intrinsic value, extension, intensity, persistence, impact_character, cumulativeness, transmissivity, and impact prevalue in four subsystems. The fifth subsystem gives the definitive impact value corresponding to the impact type of "compatible," "moderate," "severe," and "critical." The model is verified and statistically validated. Weighted Cohen's kappa shows an almost perfect concordance among experts and FESAEI's evaluations.

\section{Keywords}

Fuzzy logic

Environmental impact assessment

Fuzzy inference

Crisp numbers

\section{Introduction}

\section{AQ2}

In a survey of 98 environmental impact statements (EISs) dated between the years 2000 and 2010, we found that conventional logic and deterministic quantitative methods were used by practitioners in 57 , while the remaining 41 either used methods that were unjustified and unexplained (20) or absolutely no method (De Tomás 2015, p. 66) suggesting a predisposition to consider quantitative measurements "more scientific" than qualitative ones (Beattie 1995; De Siqueira and De Mello De Siqueira Campos Boclin and de Mello 2006) forgetting that most human activities are inspired on judgements and assumptions based on values, being these just "beliefs, either individual or social, about what is important in life" (Wilkins 2003), hence subjective and thus intrinsically categoric - not quantitative - in their essence. The results of the survey 
indicate that qualitative uncertainty analysis is avoided because it implies a lack of precision and/or knowledge (De Tomás 2015).

When working on a sample of 151 Danish strategic environmental assessments (SEAs), Larsen et al. (2013) found that uncertainties were systematically avoided or downplayed. Only five of the 151 were uncertainties acknowledged. The authors proposed two possible explanations: conflict avoidance and inability to quantify uncertainty. These hypotheses about why uncertainties are unacknowledged are consistent with arguments from evolutionary psychology about human behavior under risk and uncertainty (Sewell 2011). Despite being difficult to account for, uncertainty is almost always a significant factor in environmental impact assessment (EIA) (Tennøy et al. 2006). The use of experts' opinion and judgment is part of the current practice in EIA (Krueger et al. 2012). The information available to experts upon which to base their opinions and judgements is imperfect. The veracity of opinions and infallibility of judgements are sources of uncertainty about the accuracy of EIA conclusions (De Tomás 2015).

AQ3

AQ4

The concept of uncertainty is a key aspect that demands our attention in any and all aspects of science. While "uncertainty" is described in dictionaries by several more or less undefined clusters of concepts, the term and its sense are well captured by two emerging categories: "vagueness" and "ambiguity." "Vagueness" is commonly associated with the difficulty of achieving neat precisions; "ambiguity" has to do with the situations in which a choice between the different alternatives suitable is left unspecified (Klir and Folger 1988). Hence, it is clearly seen that the veracity of opinions and infallibility of judgements are sources of uncertainty about the accuracy of EIA conclusions (De Tomás 2015).

A sense of conviction that environmental models should incorporate the most up-to-date scientific knowledge has led to a remarkably reductionist state of EIA practice, in which the environment is divided into components which are then described precisely. This is a likely reason for the proliferation of EIA models that exclude seemingly relevant environmental 
factors or that can be applied to only certain kind of projects (De Tomás 2015). The constraints of reductionism are widely acknowledged by authors Saloranta (Saloranta 2001), Funtowicz (Funtowicz and Ravetz 1999), and others (e.g., Hunt 2000, as cited by Fisher 2006).

AQ5

AQ6

In summary, uncertainty and vagueness are always present and manifest in EIA (Mendes and Motizuki 2001; Enea and Salemi 2001), so it is incumbent upon us to develop tools to properly deal with them (Bahri et al. 2005; Shepard 2005; Bond et al. 2015).

AQ7

AQ8

Fuzzy logic has demonstrated to be a very useful approach to capture the imprecision associated with common reasoning and for the representation of human judgment models as sets of fuzzy rules (Ascough et al. 2008), and thus, it is also a good approach to cope with uncertainty (Brown 2010); furthermore, fuzzy set theory provides a systematic calculus to deal with non-parametric and vague values based on imprecise or incomplete data and opinions or subjective judgements. It performs numerical computation by using linguistic labels stipulated by membership functions. A selection of fuzzy IF-THEN rules forms the key component of a fuzzy inference system (FIS) than can effectively model human expertise in a specific application (Jang et al. 1997).

AQ9

On this paper, we propose a set of criteria for the characterization of environmental impacts and present a fuzzy logic-based inference expert system that we built using only 120 IF-THEN rules.

\section{Materials and methods}


Roughly explaining, "crisp numbers" is an assessing method that consists of a weighted additive equation to measure the "importance" of the impacts under consideration:

$$
I=(3 I n+3 E x+M o+P e+R v+S i+A c+E f+\operatorname{Pr}+M c) \quad 1
$$

where the parameters of the equation are the factors considered for the categorization of impacts - "intensity," "extension," "moment," "persistence," "reversibility," "synergy," "accumulativeness," "effect," "periodicity," "recoverability" - each of them receiving an arbitrary crisp numeric value, usually between 1 and 4 or 8 (12 for the first parameter, "intensity") with the exclusion of odd values and with the possibility of adding four extra points to any or both of two of the parameters "extension" and "moment." Once the formula is applied, a numeric value between 13 and 100 is obtained, so belonging to one of the four classes representing the value of the impact being considered: COMPATIBLE (13-25), MODERATE (26-50), SEVERE (51-75), and CRITICAL (76-113). In a further step, an arithmetic procedure is shown by which it is supposed that the practitioner will be able to calculate a "global impact" for the whole project under study.

Eq. (1) was proposed by Conesa in 1993 (Conesa 1993), then extended in 1997 (Conesa 1997) by the addition of some more parameters of impact categorization.

Still, when considering an environmental impact assessment process, we must on the first place be aware that it is all about an exercise of prediction of effects on the environment likely to be inducted by certain actions (Glasson et al. 2005). This will necessarily be impregnated of a certain degree of uncertainty which is due on one hand either to the trade-offs between different factors under consideration (Kiker et al. 2005), to an insufficient understanding of the behavior of different environmental factors or/and to the difficulty or vagueness of their measurement techniques and their variations, among others, so having an implicit lack of mathematical robustness. When involved in systems where uncertainty is implicit like environment is, the use of classical mathematics is not the best choice; when modeling this kind of systems, the mimics of human 
thinking is pursued and here, mathematical models fall short. Neither human evaluation nor judgements follow neither Boolean logic nor any other conventional mathematical approach (Bezděk 2014); this is particularly important in non-linear systems, like environmental field is, for which it is extremely difficult or neatly impossible to be described by conventional mathematical relations, which would provide unsatisfactory solutions in case they are used (Zilouchian et al. 2000). That is the main reason leading us to a fuzzy approach to assess environmental impacts.

AQ10

AQ11

Fuzzy inference is a process involving fuzzy incoming sets, fuzzy outcoming sets, and sets representing rules by which conclusions that will be reached are related. The basic structure of a fuzzy inference system is as shown in Fig. 1:

Fig. 1

Basic scheme of a Mamdani-type fuzzy inference system (authors' elaboration)

AQ12

AQ13

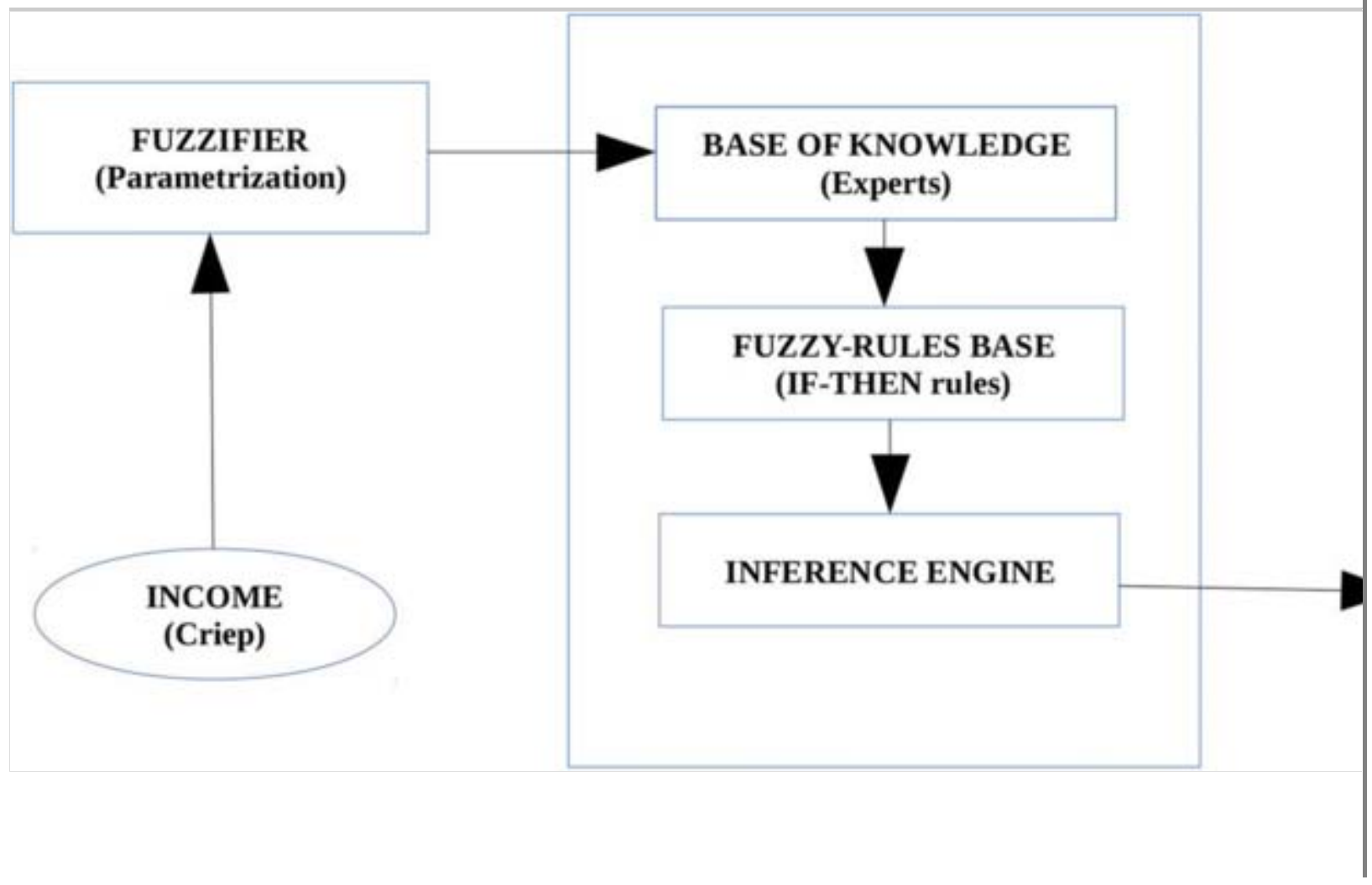


As seen in Fig. 1, system inputs are crisp numbers that when are introduced in the fuzzifier module intercept, the membership functions, being their degree of membership to one or several fuzzy sets among which the rank of all possible incoming values to the system's core is then calculated; the set of fuzzy rules is determined by experts' knowledge that comes to take matter of a reasoning process representing the behavior to be modeled. The base of rules represents the actions necessary to take a decision in the form of a set of IF-THEN sentences with a structure of causality. IF-THEN rules are interpreted by the inference engine thus gaining an outcome built upon the values representing the system's incoming linguistic variables. Finally, the defuzzifier takes the inference system's outcoming fuzzy sets to give numerical crisp values for each and any outcome depending on the fuzzy set to which they belong. To calculate the centroid or barycenter of the resulting polygonal shape, the method of aggregation was used due to its simplicity and to the fact that it is continuous; hence, a small change on incomes does not mean an abrupt change of outcomes; furthermore, it offers a single result as the process outcome (Moreno 2002). In its discrete version, this method is similar to Riemann's sum:

$$
\hat{y}=\frac{\sum_{i=1}^{n} y_{i} \cdot \mu_{B}\left(y_{i}\right)}{\sum_{i=1}^{n} \mu_{B}\left(y_{i}\right)}
$$

where $\hat{y}$ is the centroid, $\mu_{B} \mu_{B}$ is the outcome fuzzy set's membership function whose surface is being represented, and $y$ is the outcoming variable in the fuzzy set B.

AQ14

In our first approach, we tried to build one single fuzzy system; nevertheless, this needed a relatively high number of fuzzy rules (several hundreds) to properly define it (see De Tomás 2015, for more details). Splitting the system in a series of related subsystems and their posterior combination would imply the use of a much lesser number of fuzzy rules (in fact, just 120 in our case) and thus, an easier management for a proper verification. So, instead of directly building up a single system, we decided to build our model — which we called FESAEI for its acronym —in a 
simpler way, as the combination of a series of five Mamdani-type subsystems, being the outputs and input for the next subsystem. The fifth subsystem gives the definitive impact value as a crisp number between 0 and 10 . Four equal ranges $(0,2.5),(2.6,5),(5.1,7.5)$, and $(7.6,10)$ correspond to the impact values of "compatible," "moderate," "severe," and "critical," respectively.

\section{Considerations on the environmental factors susceptible of receiving impacts: characterization of environmental impacts}

Very often, practitioners are seen unnecessarily or incorrectly dealing with impacts that they assessed as "severe" or "critical" on environmental factors which in fact have themselves a non-significant or very low intrinsic value (a severe or even critical value of impact on an environmental factor of low or very low intrinsic value-i.e., a community of weeds - should not be considered as an overall "severe" or "critical" impact, as many times is seen in EIS) (De Tomás 2013, 2015). Therefore, it is necessary to properly modulate those impacts during the assessment process. To do so, we considered the "intrinsic value" of an environmental factor as the combination of two parameters: "recoverability" and "quality," the first being either "recoverable" or "unrecoverable" and the second being defined by the combination of two variables:

- Rarity. It depends on factors like its uniqueness, relative scarcity, social, cultural, public health importance and the like.

- Robustness (sensitivity to changes).

The combination of the factor's recoverability (unrecoverable-recoverable) and quality in a fuzzy subsystem would define the intrinsic value of the environmental factor being considered.

On the other hand, the proposed set of characterization parameters for the impact itself is:

- Geographic extension.

- Intensity. 
- Transmissivity.

- Persistence.

- Cumulativeness and synergy.

For all of the parameters above, we assume the definitions given by Conesa (Conesa 1997), except for "transmissivity," a new one proposed and defined by us which is defined on the footnote. As it happens with some others in the vast literature available and as we observed in the EISs that we gathered for our research, it is widely accepted that the attributes above describe well enough the impacts that can be received by environmental factors (US Environmental Protection Agency 2018), which are to be understood as "broad components of the environment" (Dahlitz and Morrison-Saunders 2015) reasons for which we decided to assume them for our model.

With respect to the environmental risks and bearing in mind that the concept is similar to usual impacts - not likely to occur, but possible-we propose a separate study based on appropriate approaches-e.g., Bayesian networks - to achieve an idea of their probability of manifestation and then proceed to their assessment by the same means used for the impacts.

\section{Model build-up}

There is no standardized method to build a fuzzy system up; nevertheless, it can be useful to follow a number of sequential steps like those proposed by Lee (1990a, 1990b), which we did; the scheme is as shown in Fig. 2:

\section{Fig. 2}

General scheme of a fuzzy system build-up process (from Lee 1990a, modified) 
Definition of goals, constraints and behavior of the Fuzzy Inference System (FIS)

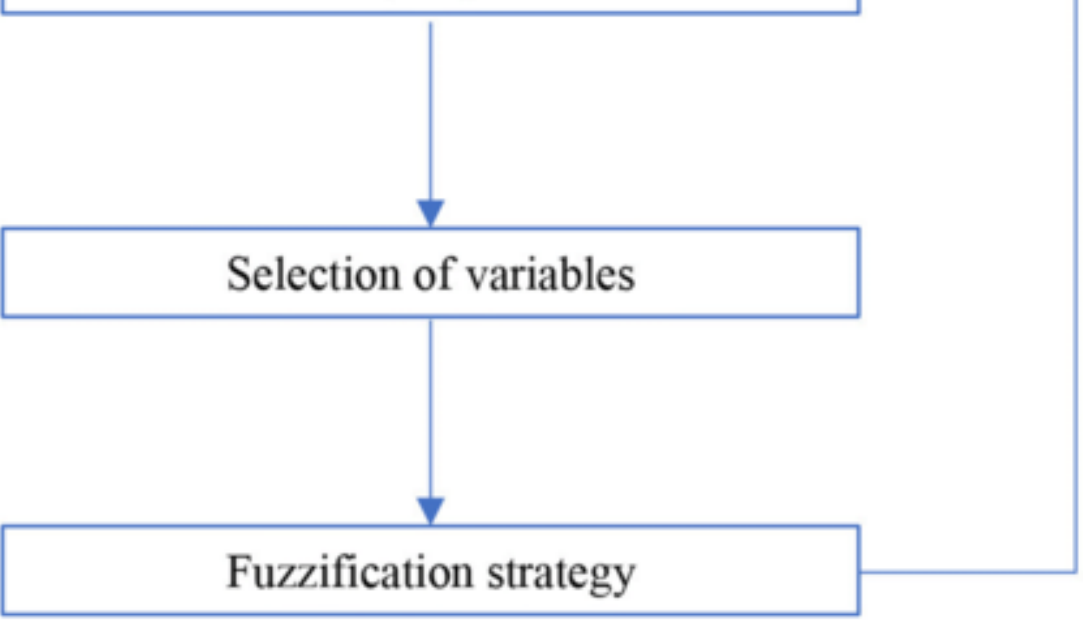

Selection of

\section{Selection of variables}

\section{Determination of the fuzzy sets}

Even though fuzzy sets can adopt a variety of shapes, we must bear in mind that trapezoidal or triangular shapes are usually sufficient to achieve a proper representation of expert knowledge; Pislaru suggests the use of triangular or trapezoidal functions to represent aspects related to environment (Pislaru and Trandabat 2011, p. 71).

AQ15

AQ16

Fuzzy rules' base build-up

A total of 120 fuzzy rules were constructed with the help of consultations to experts.

Encoding of fuzzy sets, fuzzy rules, and inference procedures

Fuzzy Toolbox (MatLab)® and Mamdani’s inference algorithm with triangular functions were used for our model.

Model's assessment and fitting: verification and validation

Verification The Surface Viewer of Fuzzy Logic Toolbox ${ }^{\circledR}$ was used for 
the verification of the systems. It allowed us to analyze the fuzzy rule sets' consistency and was an excellent and very helpful tool for making necessary corrections on some fuzzy rules leading to a discordant behavior of the systems when discontinuities or abrupt changes on the slope were observed.

Validation For the validation of FESAEI, 20 EISs previously having had their impact declaration by the environmental authority were gathered; then, three impacts were randomly extracted from each one, thus having a collection of 60 impacts which had been previously assessed by experts' panel discussion; thus, each individual's impact value represents the consensus of several experts' opinions contributing to the final judgements; and that is how we consider each single impact. Each value belongs to one of the four classes admitted by European regulations: "compatible" (C), "moderate" (M), "severe" (S), or "critical" (CR).

The same impacts were then evaluated using FESAEI and the results of both experts and FESAEI's evaluations were disposed in a table upon which, frequency tables were built; then, since $75 \%$ (12 out of 16 ) of the expected values are lower than 5, a Chi-square test is not a reliable option as an independence test (Lewis and Burke 1949) and a two-tailed Fisher's exact test was applied instead.

The contingency tables obtained were as follows (letters C, M, S, and CR refer to compatible, moderate, severe, and critical, respectively):

Being the results a set of categorical data, Cohen's kappa test, $\kappa$, was applied to study the concordance of experts and FESAEI's results. Cohen's kappa index was calculated upon the equation:

$$
\kappa=\frac{F o-F e}{1-F e}
$$

where $\mathrm{Fo}$ and $\mathrm{Fe}$ are the observed and expected frequencies, respectively.

Nevertheless, given that the four categories of impact classification can be (and, in fact, they are) ordered from less to more importance, and in order to properly consider the fact that the order or the differences eventually observed between the results according to the experts on one hand, and the 
model on the other (differences of one or more classes between both judgements), the said results have to be weighted to obtain weighted Cohen's kappa, $\kappa_{\mathrm{w}}$, which would offer a much better idea of the index of concordance between experts and FESAEI's results. To do so, the level of agreement between the values obtained from both experts and FESAEI was weighted from 0 to 3 , representing 0 , a full agreement; 3 , a full disagreement; and 1 and 2, intermediate levels of agreement and then operated with the values in the contingency table previously obtained. Weighted Cohen's kappa was calculated upon the equation:

$$
\kappa_{w}=\frac{F o_{w}-F e_{w}}{1-F e_{w}}
$$

where $\mathrm{Fo}_{w}$ and $\mathrm{Fe}_{w j}$ are the weighted observed and expected frequencies, respectively (Fleiss and Cohen 1973).

\section{Results}

As stated in the previous section, five related Mamdani-type subsystems were built, being the output of a subsystem an input for the following one. These are described below by some of their rules.

\section{Subsystem 1 (QUALITY)}

According to the procedure described above, we built subsystem 1 (QUALITY) to obtain the parameter "quality"; to do so, we assessed parameters "rarity" and "robustness" that were the inputs processed by a set of 17 fuzzy rules, some of which are:

- Rule \#3: If (rarity is Low) and (robustness is very_low) then (QUALITY is low)

- Rule \#7: If (rarity is low) and (robustness is very_high) then (QUALITY is very_low)

- Rule \#16: If (rarity is high) and (robustness is high) then (QUALITY is high)

Figure 3 shows the consistency of subsystem 1 . 
Fig. 3

MatLab's outprint showing the consistency of subsystem 1. Obtained using Fuzzy Toolbox Surface Viewer

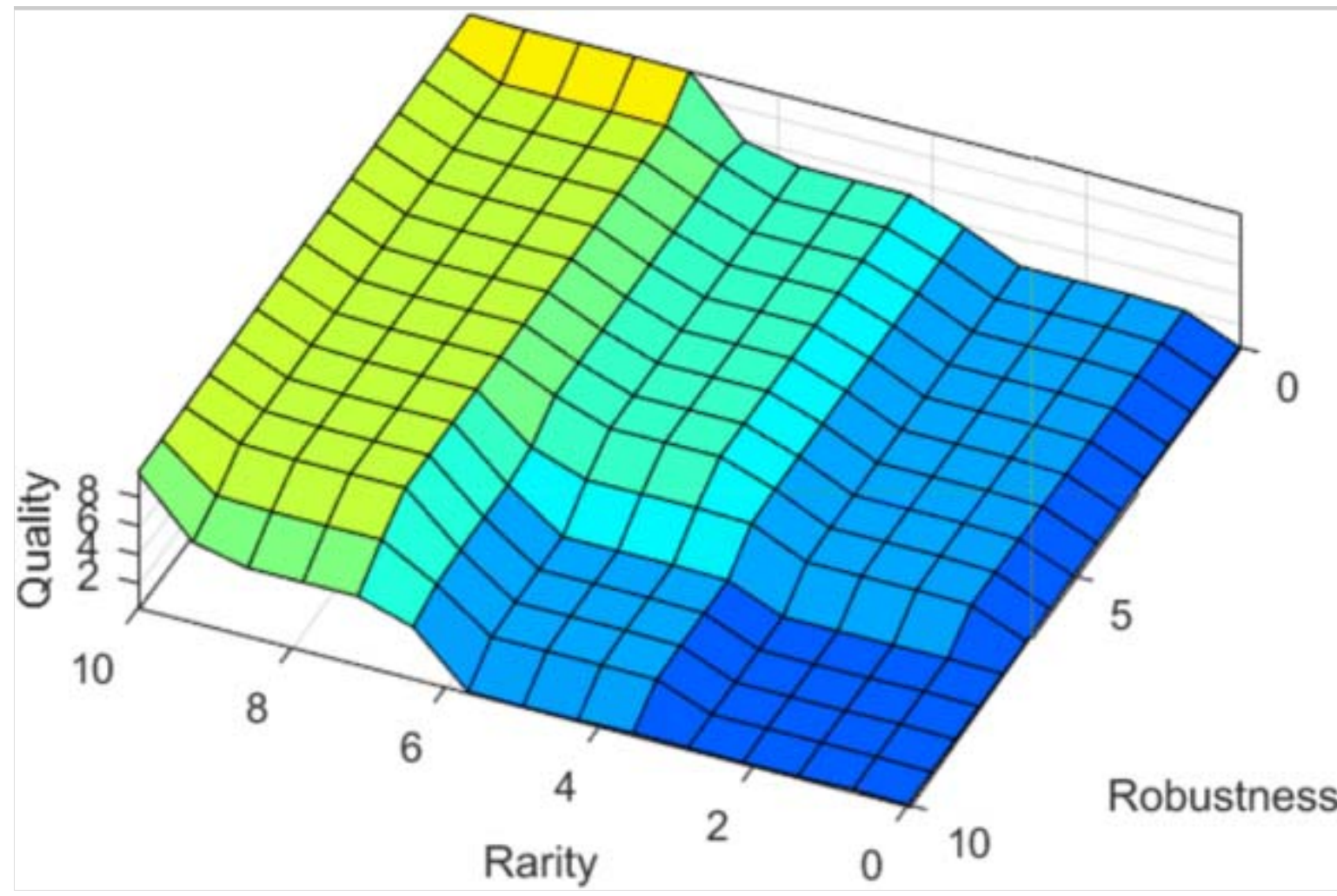

\section{Subsystem 2 (IMPACT_CHARACT)}

The inputs to the system are "extension," "intensity," and "persistence," being the output "impact_character"; a set of 36 fuzzy rules was used, some of them being:

Rule \#8: If (extension is punctual) and (intensity is high) and (persistence is temporal) then (impact_charact is compatible)

Rule \#14: If (extension is local) and (intensity is medium) and (persistence is temporal) then (impact_charact is moderate)

Rule \#33: If (extension is very_extense) and (intensity is medium) and (persistence is permanent) then (impact_charact is severe)

Figures 4, 5, and 6 show the consistency of all aspects combinations of 
subsystem 2 .

Fig. 4

MatLab's outprint showing the logical consistency of intensity and extension aspects in subsystem 2. Obtained using Fuzzy Toolbox Surface Viewer

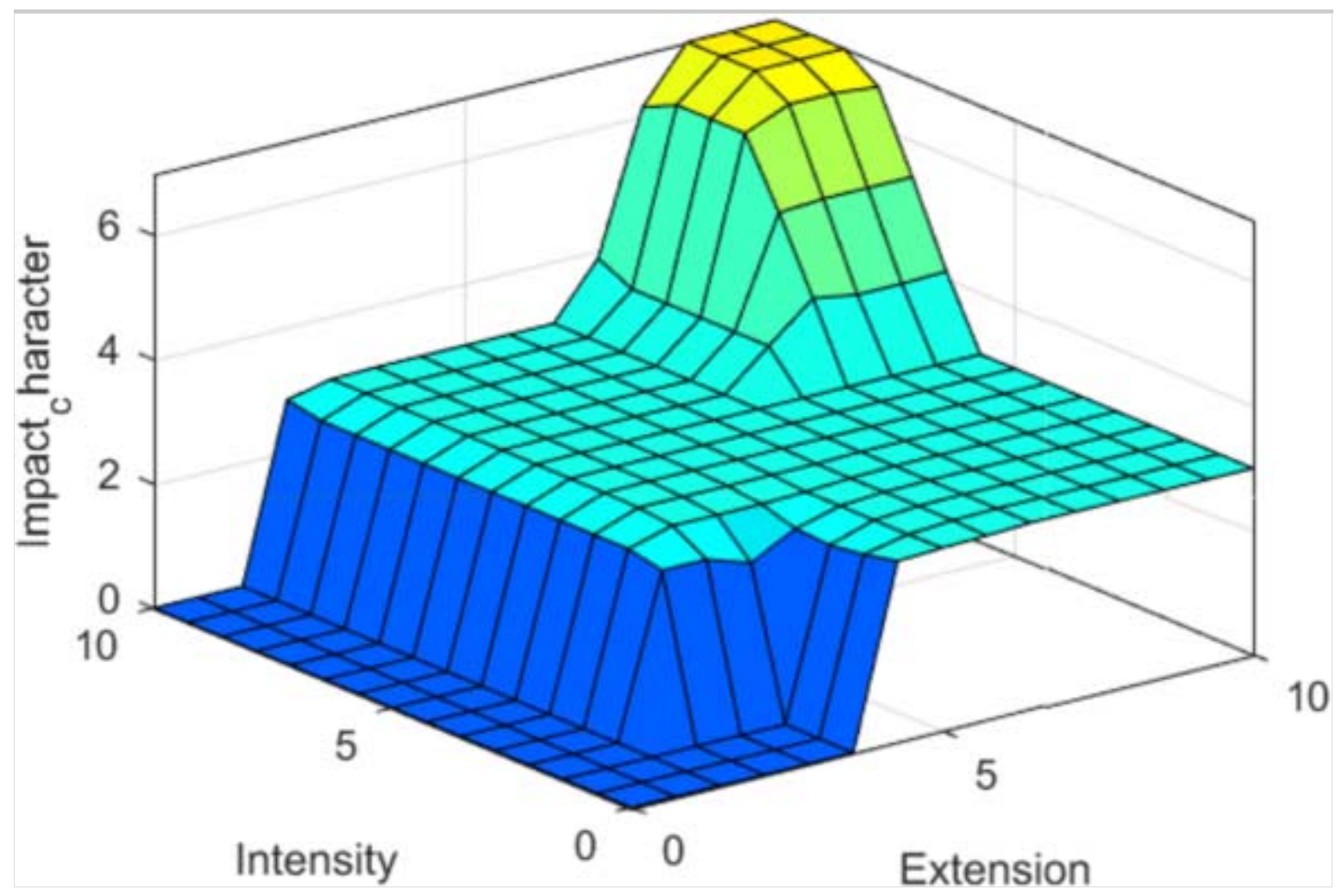

Fig. 5

MatLab's outprint showing the logical consistency of intensity and persistence aspects in subsystem 2. Obtained using Surface Viewer 


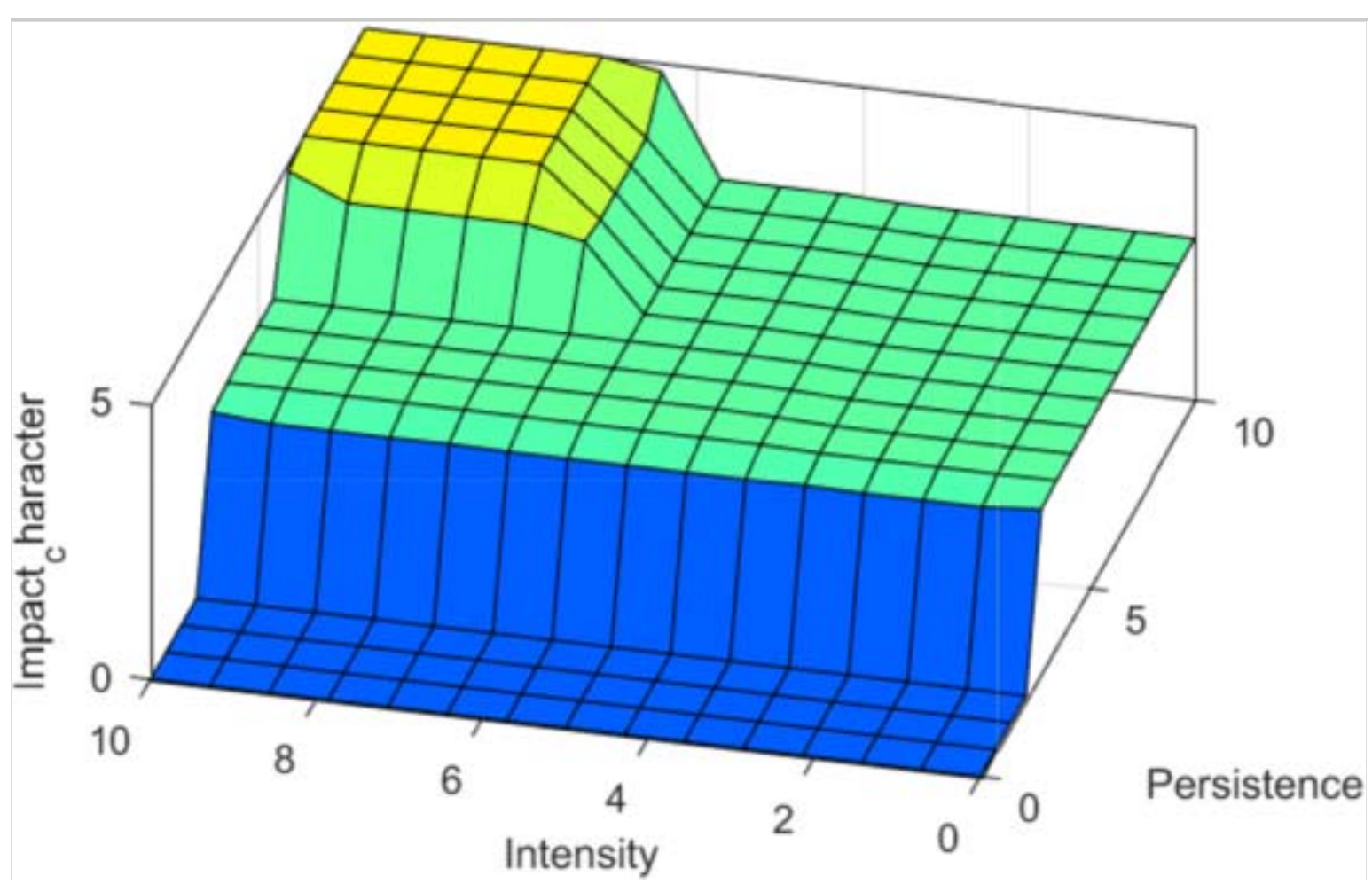

Fig. 6

MatLab's outprint showing the logical consistency of persistence and extension aspects in subsystem 2. Obtained using Fuzzy Toolbox Surface Viewer 


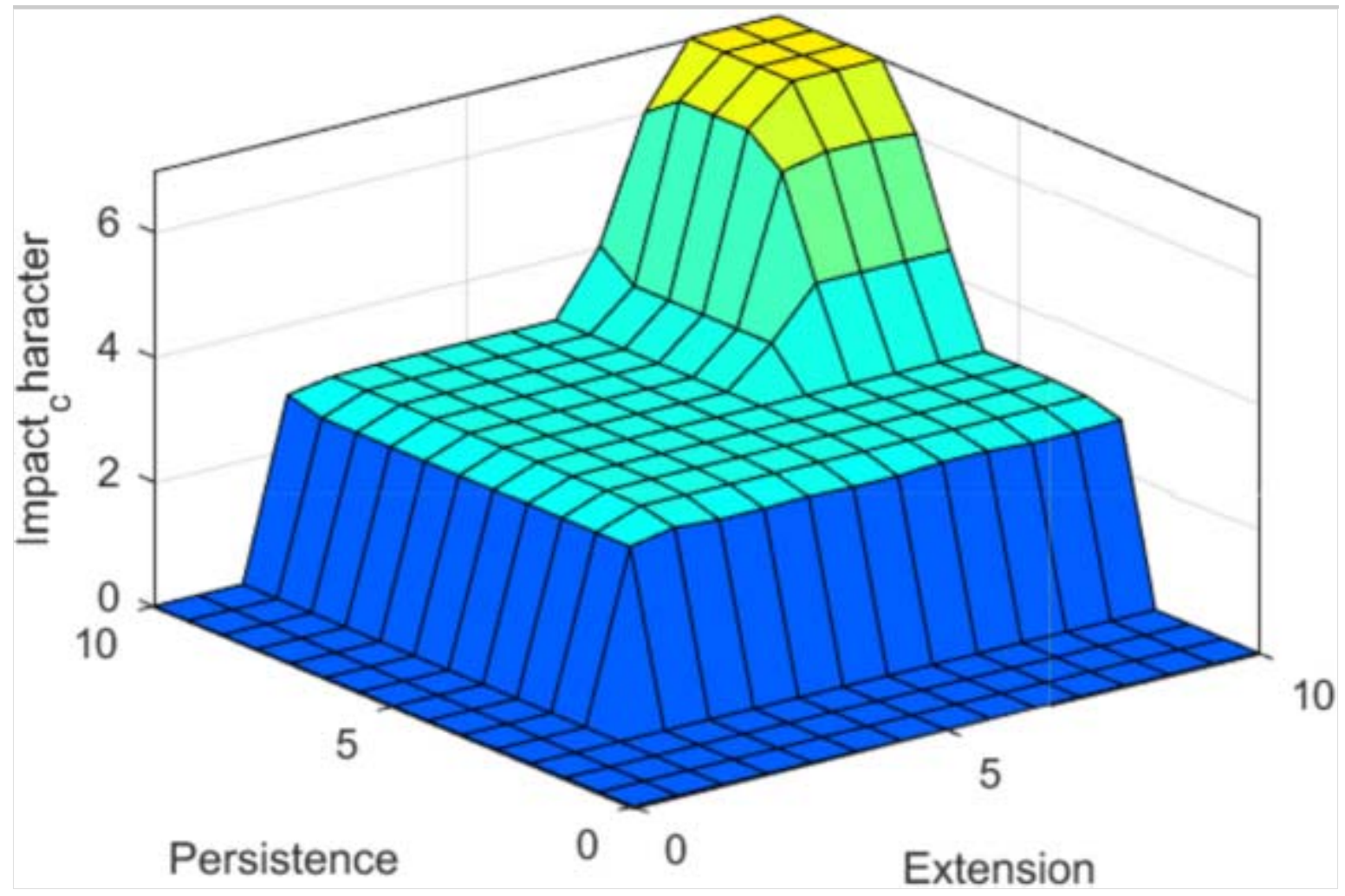

\section{Subsystem 3 (PREVALUE)}

The inputs are "IMPACT_CHARACT" (output of subsystem 2)

Cumulativeness and Transmissivity, being "PREVALUE" (the value of the impact before being modulated by the intrinsic value of the environmental factor receiving it) the output; the system is controlled by a set of 36 fuzzy rules, being some of them:

Rule \#3: If (impact_charact is compatible) and (cumulativeness is simple) and (transmissivity is high) then (PREVALUE is moderate)

Rule \#15: If (impact_charact is moderate) and (cumulativeness is cumulative) and (transmissivity is high) then (PREVALUE is severe)

Rule \#27: If (impact_charact is severe) and (cumulativeness is synergic) and (transmissivity is high) then (PREVALUE is critical).

Figures 7, 8, and 9 show the consistency of all aspects combinations of subsystem 3 .

Fig. 7 
MatLab's outprint showing the logical consistency of cumulativeness and impact character aspects in subsystem 3. Obtained using Fuzzy Toolbox Surface Viewer

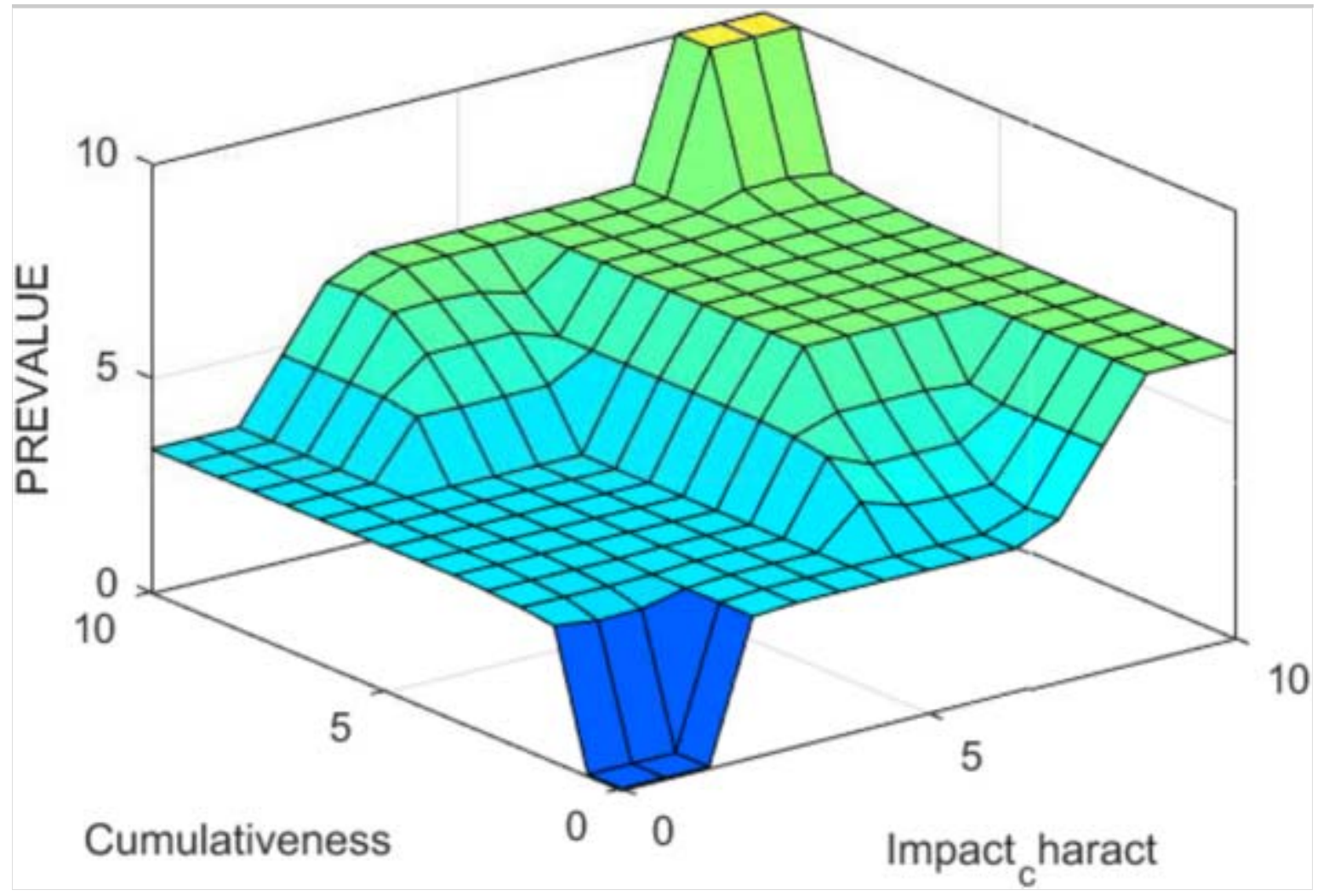

Fig. 8

MatLab's outprint showing the logical consistency of cumulativeness and transmissivity aspects in subsystem 3. Obtained using Fuzzy Toolbox Surface Viewer 


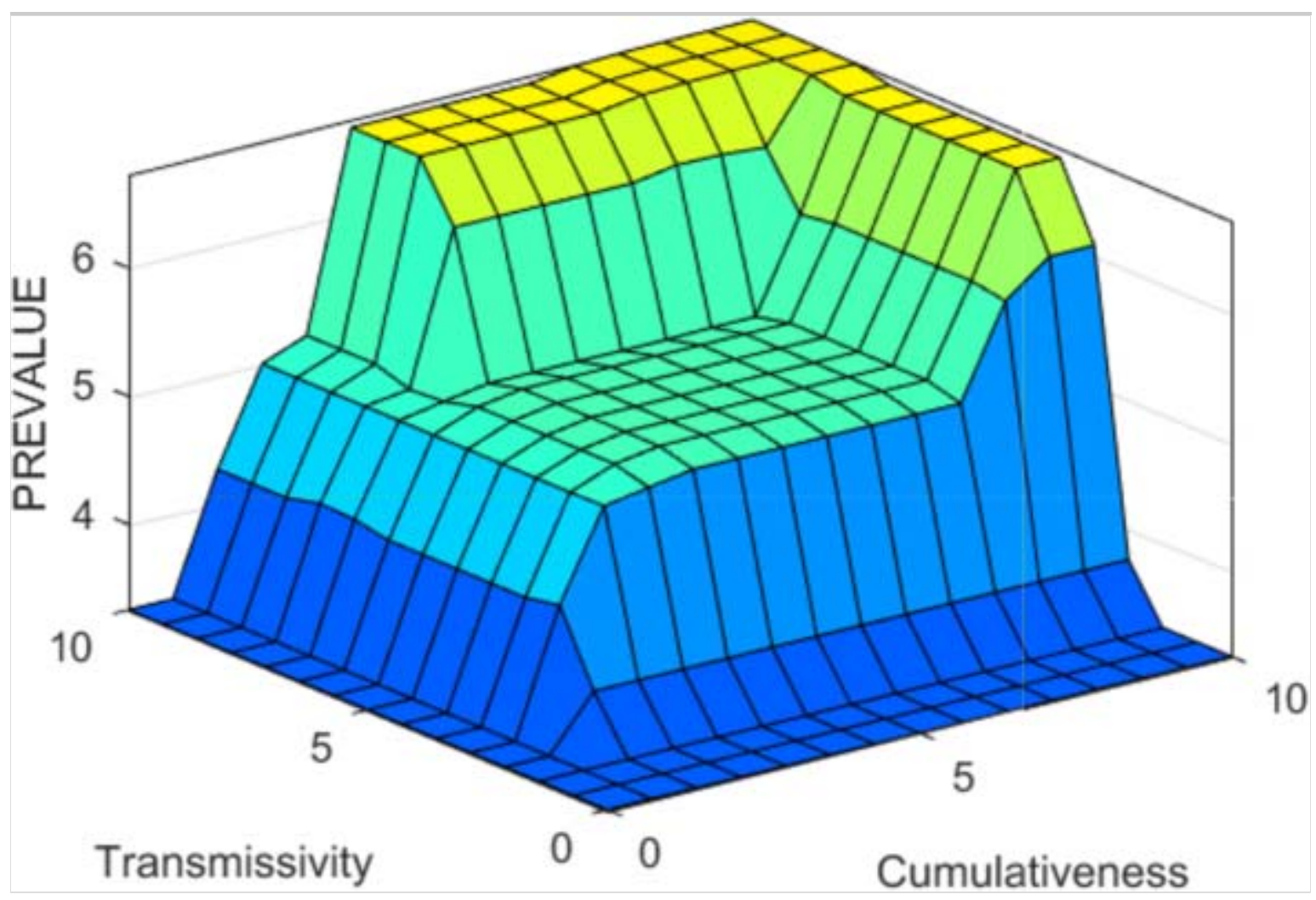

Fig. 9

MatLab's outprint showing the logical consistency of transmissivity and impact character aspects in subsystem 3. Obtained using Fuzzy Toolbox Surface Viewer 


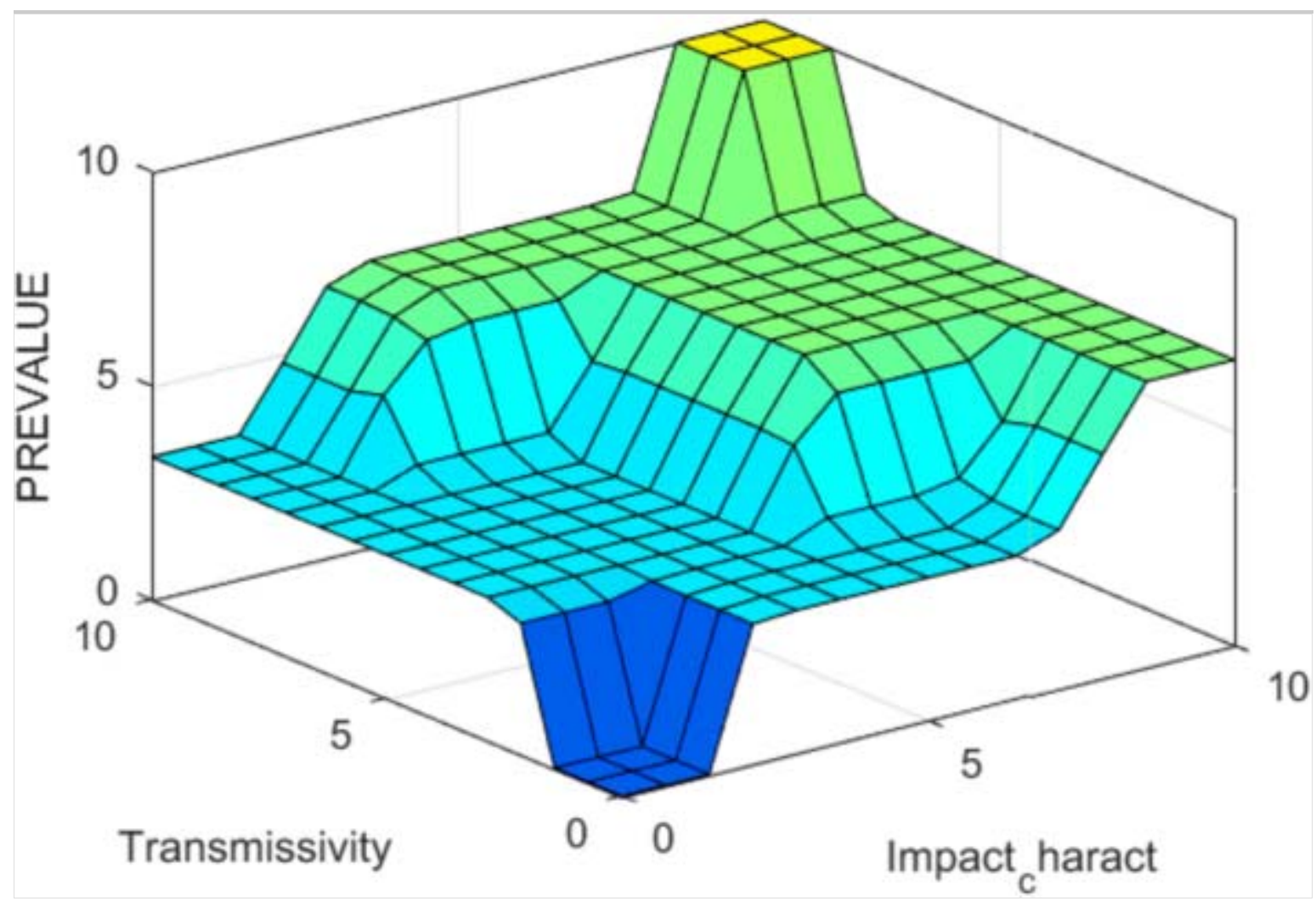

\section{Subsystem 4 (INTR_VALUE)}

The inputs are "QUALITY" and "recoverability," being "intrinsic value" the output of the system; a set of fuzzy nine rules was used, some of which are:

Rule \#1: If (recoverability is recoverable) and (QUALITY is very_low) then (INTR_VALUE is very_low)

Rule \#5: If (recoverability is recoverable) and (QUALITY is very_high) then (INTR_VALUE is high)

Rule \#9: If (recoverability is non-recoverable) and (QUALITY is very_high) the (INTR_VALUE is very_high)

Figure 10 shows the logical consistency of subsystem 4 .

Fig. 10

MatLab's outprint showing the consistency of subsystem 4. Obtained using Fuzzy Toolbox Surface Viewer 


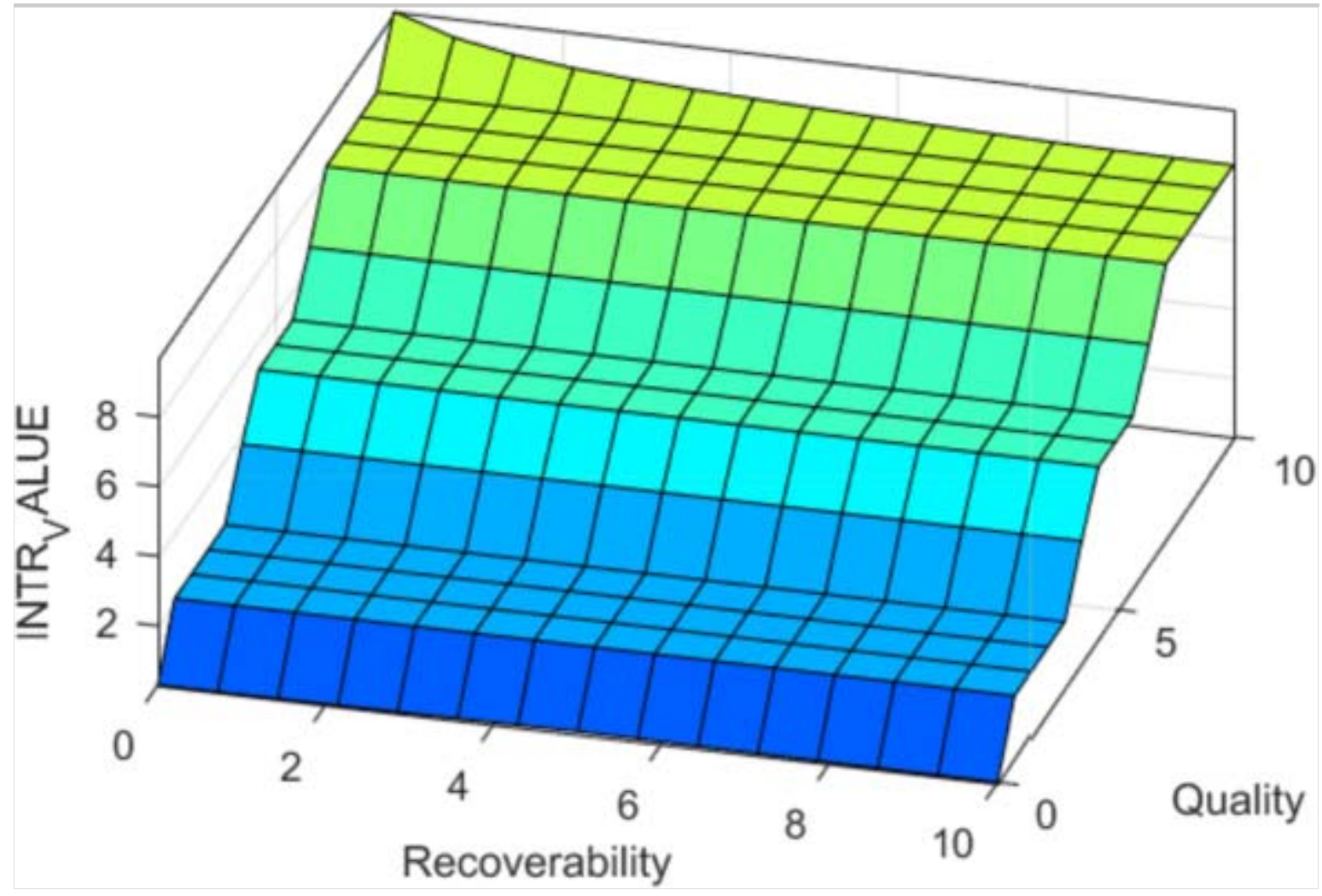

\section{Subsystem 5 (IMPACT)}

The last of the subsystems represents the modulation of the impact value by computing the PREVALUE assessed for the impact with the intrinsic value of the environmental factor receiving it and offers the final value of the impact. Thus, the inputs are INTR_VALUE and PREVALUE. This is performed by a set of 22 fuzzy rules:

Rule \#9: If (PREVALUE is moderate) and (INTR_VALUE is medium) then (IMPACT is MODERATE)

Rule \#14: If (PREVALUE is severe) and (INTR_VALUE is medium) then (IMPACT is MODERATE)

Rule \#21: If (PREVALUE is critical) and (INTR_VALUE is high) then (IMPACT is CRITICAL).

Figure 11 shows the consistency of subsystem 5 (final output).

Fig. 11

MatLab's outprint showing the consistency of subsystem 5. Obtained using 


\section{Fuzzy Toolbox Surface Viewer}

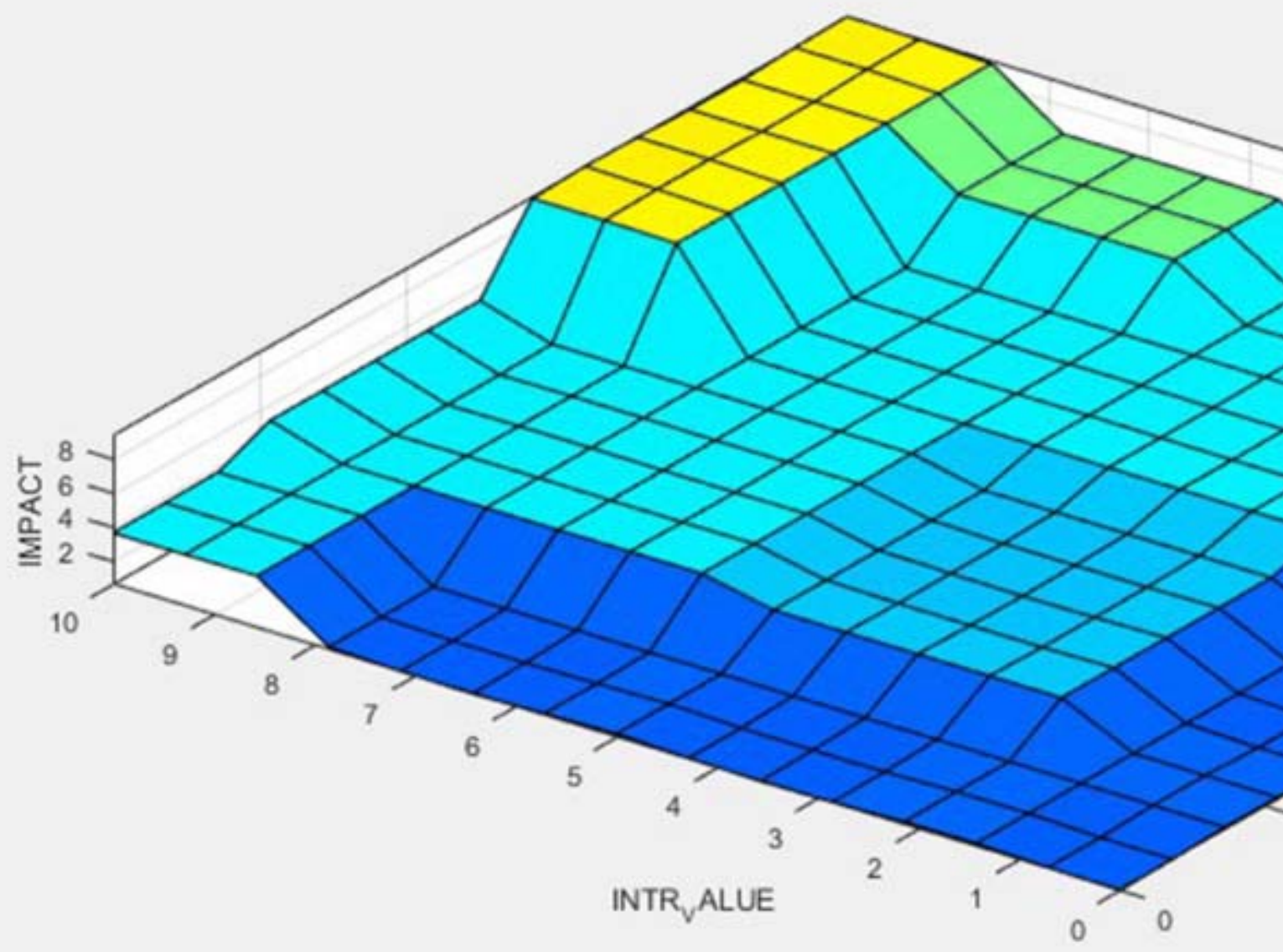

\section{Model's validation}

The validation process takes in consideration 20 EISs, three randomly selected impacts of each one of the, thus giving a total of 60 impacts. Fisher's exact test (obtained using the statistic software Minitab) shows that the null hypothesis should be rejected thus accepting the alternative hypothesis (probability of a type I error $<0.09 \%$ ).

\section{Fisher's exact test}

$p$ value (two-tailed)

0.001

A

0.95 


\section{Determinations of concordance between experts and FESAEI's results}

The concordance between both experts and the model's results was evaluated by Fleiss' kappa index. The result of the application of Eq. (3) was $\kappa=0.717$, which is after Landis (Landis and Koch 1977), indicates a "substantial" concordance between the results obtained by experts and by FESAEI. Despite the good value of $\kappa$, in this case, it is still necessary to consider the "distance" between experts and FESAEI's results for a same impact (Table 1); we did so by weighting the degrees of separation of the values respectively offered from 0 (denoting full agreement) to 3 (full disagreement). Thus, applying Eq. (4), an even better result of $\kappa_{\mathrm{w}}=0.9958$ ("almost perfect" concordance) among experts and FESAEI's evaluations was obtained. Table 2 .

\section{Table 1}

Contingency table of data showing observed frequencies AQ18

\begin{tabular}{|c|c|c|c|c|}
\hline \multirow{2}{*}{ FESAEI } & \multicolumn{4}{|c|}{ Experts } \\
\hline & $\mathrm{C}$ & $\mathbf{M}$ & $\mathbf{S}$ & CR \\
\hline $\mathrm{C}$ & 14 & 3 & 0 & 0 \\
\hline M & 5 & 22 & 0 & 0 \\
\hline S & 0 & 0 & 7 & 0 \\
\hline $\mathrm{CR}$ & 0 & 0 & 4 & 5 \\
\hline
\end{tabular}




\section{Table 2}

Expected (theoretical) frequencies

\begin{tabular}{|c|c|c|c|c|}
\hline \multirow{2}{*}{ FESAEI } & \multicolumn{4}{|c|}{ Experts } \\
\hline & $\mathrm{C}$ & M & $\mathbf{S}$ & CR \\
\hline $\mathrm{C}$ & 5.38 & 7.08 & 3.12 & 1.42 \\
\hline M & 8.55 & 11.25 & 4.95 & 2.25 \\
\hline S & 2.22 & 2.92 & 1.28 & 0.58 \\
\hline $\mathrm{CR}$ & 2.85 & 3.75 & 1.65 & 0.75 \\
\hline
\end{tabular}

AQ17

\section{Discussion}

FESAEI has been verified in its structure, statistically validated and tested in more than 20 cases of EIS by now, demonstrating its usefulness for assessing environmental impacts while incorporating uncertainties in the process, showing a consistency and mathematic robustness lacking in other methodologies preferred by practitioners (Zilouchian et al. 2000; Bezděk 2014), which, as said before, do not include at all in their processes the concepts of uncertainty and/or incompleteness of data or knowledge. It provides a simple, robust, and effective method for EIA.

The system's performance has been tested in a number of cases proving its usefulness as an appropriate means to assess environmental impacts while incorporating uncertainties in the process with a consistency and mathematic robustness not present in some other methodologies that are currently the preferred choice by practitioners, such as the aforementioned "crisp numbers" method (Zilouchian et al. 2000; Bezděk 2014).

Furthermore, it provides a simple, robust, and effective method for a quick environmental impact assessment.

An additional feature of FESAEI is that it considers the often-overlooked intrinsic importance of the environmental attributes in the model, making it possible to discriminate cases in which an impact is irrelevant. This is 
particularly useful for novice - and even not so novice - practitioners who are prone to inadequately scope out the EIA and consequently overestimate impacts that should be considered as irrelevant. Also, FESAEI allows working with quantitative and qualitative data at the same time while considering uncertainty.

The system's performance has been tested in a number of cases proving its usefulness as an appropriate means to assess environmental impacts while incorporating uncertainties in the process showing a consistency and mathematic robustness not present in some other methodologies that are currently the preferred choice by practitioners, such as the aforementioned "crisp numbers" method. Furthermore, it provides a simple, robust, and effective method for a quick environmental impact assessment.

An additional feature of our fuzzy inference expert model is that the values obtained for the impacts consider the often-bypassed aspect of the intrinsic importance of the environmental aspect receiving them, which makes it possible to discriminate the cases mentioned above, in which an impact of a certain consideration shall really be judged even as irrelevant, depending on the quality of the environmental factor. This is particularly useful for novel - and even not so novel-practitioners who very often have not conducted a previous and correct scoping and overestimate some impacts which should really be considered as irrelevant. Also, FESAEI allows working with both quantitative and qualitative data at the same time while taking uncertainty into account.

Unlike other models, whether they are based in a fuzzy point of view or not, which are intended for a restricted use in a few types of projects, our model was designed from a non-reductionist approach and allows its use on the assessment of environmental impacts derived from whatever action over any natural or semi-natural systems.

\section{Conclusions}

FESAEI is a fuzzy expert system for the assessment of environmental impacts, an expert system built upon the fuzzy logic approach using MatLab's ${ }^{\circledR}$ Fuzzy Logic Toolbox. The system is composed by five subsystems that are sequentially ran from first to fifth and being the output 
of each subsystem the input for the next one uses a total of 120 fuzzy rules. The use of the five sub-sets of fuzzy rules, all of them having a triangular geometry, implies the consideration and computation of uncertainty and vagueness concerning data and lacks of knowledge or precision regarding environmental issues which, for different reasons are quite often overlooked by practitioners. After verification and validation, the system showed an "almost perfect" concordance between FESAEI and experts" evaluation. FESAEI has shown its capabilities as a tool that offers a very useful method for assessing environmental impacts in a rapid and easy way.

\section{Acknowledgements}

The authors wish to acknowledge the contributions of Dr. Eduardo Seva, Dr. Josep Raventós, Dr. Germán López, Dr. José E. Martínez, and Dr. Juan Ramón Sánchez, for their invaluable observations and especially to Dr. Aitor Forcada for his warm support and orientation in statistical concerns.

\section{References}

Ascough, J. C., et al. (2008). Future research challenges for incorporation of uncertainty in environmental and ecological decisionmaking. Ecological Modelling, 219(3-4), 383-399. https://doi.org /10.1016/j.ecolmodel.2008.07.015 .

Bahri, A., Chakhar, S. and Na, Y. (2005) 'Implementing imperfect information in fuzzy databases', in International Symposium on Computational Intelligence and Intelligent Informatics. Hammamet, pp. $1-8$.

Beattie, R. B. (1995). Everything you already know about EIA (but don't often admit). Urban Studies, 9255(95), 109-114. https://doi.org /10.1016/0195-9255(95)00001-U .

Bezděk, V. (2014). Using fuzzy logic in business. Procedia - Social and Behavioral Sciences, 124, 371-380. https://doi.org/10.1016 /j.sbspro.2014.02.498 . 
Bond, A., Morrison-Saunders A., Gunn J.A.E., Pope J., Retief F. (2015) 'Managing uncertainty, ambiguity and ignorance in impact assessment by embedding evolutionary resilience, participatory modelling and adaptive management', Journal of Environmental Management. Elsevier Ltd, 151, pp. 97-104. https://doi.org/10.1016 /j.jenvman.2014.12.030 .

Brown, J. D. (2010). Prospects for the open treatment of uncertainty in environmental research. Progress in Physical Geography, 34(1), 75-100. https://doi.org/10.1177/0309133309357000 .

Conesa, V. 1993. Guía Metodológica Para La Evaluación Del Impacto Ambiental. 1st ed. Madrid: Mundi Prensa. https://books.google.com.co /books?id=GW8lu9Lqa0QC .

Conesa, V. (1997). Guía Metodológica Para La Evaluación Del Impacto Ambiental (3rd ed.). Madrid: Mundi Prensa.

Dahlitz, V., \& Morrison-Saunders, A. (2015). Assessing the utility of environmental factors and objectives in environmental impact assessment practice: Western Australian insights. Impact Assessment and Project Appraisal, 33(2), 142-147. https://doi.org/10.1080 /14615517.2014.981057 .

De Siqueira Campos Boclin, A., \& de Mello, R. (2006). A decision support method for environmental impact assessment using a fuzzy logic approach. Ecological Economics, 58(1), 170-181. https://doi.org /10.1016/j.ecolecon.2005.06.007 .

De Tomás, J.-E. 2013. Estudios de Impacto Ambiental. Manual Práctico Para Su Elaboración. Alicante: Publicaciones de La Universidad de Alicante. I. Alicante: Universidad de Alicante.

De Tomás, J.-E. 2015. “Tres Décadas de Evaluación Del Impacto Ambiental En España. Revisión, Necesidad Y Propuestas Para Un Cambio de Paradigma." : 281. http://rua.ua.es/dspace/bitstream/10045 /48910/1/tesis_de_tomas_sanchez.pdf . 
Fleiss, J. L., \& Cohen, J. (1973). The equivalence of weighted kappa and the intraclass correlation coefficient as measures of reliability. Educational and Psychological Measurement, 33, 613-619.

Funtowicz, S., \& Ravetz, J. (1999). Information tools for environmental policy under conditions of complexity. Environmental issues series European Environment Agency, 9, 1-34 Available at: http://www.pedz.uni-mannheim.de/daten/edz-bn/eua/00/envissue09.pdf

Klir, G. J., \& Folger, T. A. (1988). Fuzzy sets, uncertainty, and information. NJ. Prentice-Hall: Englewood Cliffs.

Krueger, T., Page T., Hubacek K., Smith L., Hiscock K. (2012) 'The role of expert opinion in environmental modelling', Environmental Modelling and Software. Elsevier Ltd, 36, pp. 4-18. https://doi.org /10.1016/j.envsoft.2012.01.011 .

Landis, J. R., \& Koch, G. G. (1977). The measurement of observer agreement for categorical data. Biometrics, 33(1), 159. https://doi.org $/ 10.2307 / 2529310$.

Larsen, S. V., Kørnøv, L., \& Driscoll, P. (2013). Avoiding climate change uncertainties in strategic environmental assessment.

Environmental Impact Assessment Review, 43, 144-150. https://doi.org /10.1016/j.eiar.2013.07.003 .

Lee, C. C. (1990a). Fuzzy logic in control systems: fuzzy logic controller - part I. IEEE System Man and Cybernetics, 20(2), 419-435 http://ieeexplore.ieee.org/lpdocs/epic03/wrapper.htm?arnumber=52552 .

Lee, C. C. (1990b). Fuzzy logic in control systems: fuzzy logic controller - part II. IEEE System, Man and Cybernetics, 20(2), 419-435 http://ieeexplore.ieee.org/lpdocs/epic03/wrapper.htm?arnumber=52552 .

Lewis, D., \& Burke, C. J. (1949). The use and misuse of the chi-square test. Psychological Bulletin, 46, 433-489. 
Saloranta, T. M. (2001). Post-normal science and the global climate change. Climatic Change, 50, 395-404.

Sewell, M. (2011) 'Human behaviour under risk and uncertainty are we really just conservative?', in App. Env. Econ. Conference. London, pp. $1-4$.

Shepard, R. (2005). Quantifying environmental impact assessment using fuzzy logic. I. New York: Springer.

US Environmental Protection Agency. (2018). Statement of environmental principles, factors and objectives environmental protection authority. EPA: US Environmental Protection Agency http://www.epa.wa.gov.au/guidelines-and-procedures/statementenvironmental-principles-factors-and-objectives .

Wilkins, H. (2003). The need for subjectivity in EIA: discourse as a tool for sustainable development. Environmental Impact Assessment Review, 23(4), 401-414. https://doi.org/10.1016/S0195-9255(03)00044-1 .

Zilouchian, A., Juliano, M., Healy, T., \& Davis, J. (2000). Design of a fuzzy logic controller for a jet engine fuel system. Control Engineering Practice, 8(8), 873-883. https://doi.org/10.1016 /S0967-0661(00)00019-8 .

Tennøy, A., Kværner, J., \& Gjerstad, K. I. (2006). Uncertainty in environmental impact assessment predictions: the need for better communication and more transparency. Impact Assessment and Project Appraisal, 24(1), 45-56. https://doi.org/10.3152/147154602781766627

Hunt, J., 2000, Mathematics and Environmental Problems methodologies and future developments. NERC-EPSRC Workshop, July 18, 2000. Ireland,

Fisher, B.E.A. 2006. "Fuzzy Approaches to Environmental Decisions: Application to Air Quality." Environ. Sci. Policy 9(1): 22-31 
Mendes, J.F.; Motizuki, W.S. 2001. "Urban Quality of Life Evaluation Scenarios : The Case of São Carlos in Brazil." CTBUH Counc. Rep. 1(2): $1-11$.

Enea, M.; Salemi, G. 2001. Fuzzy approach to the environmental impact evaluation. Ecological Modelling, 136(2-3), pp.131-147.

Jang, J-S.R.; Sun, C.T.; Mizutani, E. 1997. Neuro-Fuzzy and Soft Computing: A Computational Approach to Learning and Machine Intelligence. Prentice Hall.

Glasson, J., Thérivel, R., \& Chadwick, A. (2005). Introduction to environmental impact assessment (3rd ed., Vol. 3). New York: Routledge. https://doi.org/10.4324/9780203023068

Kiker, G. A., Bridges, T. S., Varghese, A., Seager, T. P., \& Linkov, I. (2005). Application of multicriteria decision analysis in environmental decision making. Integrated Environmental Assessment and Management, 1(2), 95-108. https://doi.org/10.1897/IEAM_2004a-015.1

Moreno, F..J. 2002. "Un Entorno de Desarrollo Para Sistemas de Inferencia Complejos Basados En Lógica Difusa." University of Sevilla. https://idus.us.es/xmlui/handle/11441/15704.

Pislaru, M.; Trandabat, A. 2011. "Decision Suport Tool Based on Neuro-Fuzzy Environmental Approach." In International Conference on Environmental Engineering and Applications, Singapore, 68-73.

1 Defined as the capability of a geographic spreading of the impact to larger areas (e.g., aquatic or atmospheric pollution). 